\title{
Principais características da ação da melatonina no corpo humano: uma revisão literária
}

\author{
Main characteristics of the action of melatonina in the human body: a literary review \\ Principales características de la acción de la melatonina em el cuerpo humano: uma \\ revisíon literaria
}

Diana Babini Lapa de Albuquerque Britto ${ }^{1 *}$, Luis Filipi Souza de Britto Costa1 ${ }^{1}$ Bruno Mendes Tenório $^{2}$, Carina Scanoni Maia ${ }^{1}$, José Anderson da Silva Gomes ${ }^{1}$, Geovanna Hachyra Facundo Guedes $^{1}$, Maria Luísa Figueira de Oliveira ${ }^{1}$, Juliana Pinto de Medeiros ${ }^{1}$, Vanessa Silva Lapa ${ }^{3}$, Fernanda Chagas Ângelo Mendes Tenório'.

\section{RESUMO}

Objetivo: descrever as principais características da ação da melatonina sobre o corpo humano. Revisão Bibliográfica: Atualmente, pesquisas vêm acontecendo com propósito de descobrir cada vez mais sobre as ações da melatonina (MEL) em humanos. A literatura descreve como sendo o hormônio do sono, fundamental no ritmo circadiano do corpo humano. Diversas ações fisiológicas da MEL ocorrem através da sua interação com receptores de membrana, chamados: MT1 e MT2. Além disso, apresenta um papel importante durante o ciclo da vida. Atingem os maiores valores nos niveis séricos no desenvolvimento da criança e fase prépubere. Sofre diminuição progressiva na puberdade, descrescendo bastante com 0 envelhecimento. Atualmente os estudos relatam que a MEL vem apresentando ação antioxidante, antiinflamatória, antioncostática e, também, na eliminação de radicais livres. Também apresenta ação otoprotetora, importante ação na placenta no período gestacional e ainda atua no sistema genital feminino. Considerações finais: Conclui-se, desta forma, que a melatonina tem um papel fundamental no ritmo circadiano do corpo humano bem como em tratamento com ações protetoras no corpo, podendo, ser utilizado em pesquisas para que haja um maior avanço científico através da sua aplicabilidade em diversas áreas da saúde que poderão ser aplicadas futuramente em tratamento cada vez mais específico.

Palavras-chave: Melatonina, Sono, Humanos, Proteção.

\begin{abstract}
Objective: To describe the main characteristics the action of melatonina on the human. Bibliographic Review: Currently, research has been going to discover more and more about actions of melatonina (MEL) in humans. The literature describes as the sleep hormone, fundamental in the circadian rhythm of the human. Several physiological actions MEL occur through its interaction with membrane receptors, called: MT1 and MT2. In addition, it plays important role during the life cycle. They reach the highest values in sérum levels in child development and prepuberal phase. It under goesa progressive decrease in puberty, decreasing significantly with aging. Currently, studies report that MEL has been chowing antioxidante, antiinflammatory, anthioncostatic action and also in the elimination of free radicals. It also has na otoprotective action, na importante action on the placenta during pregnancy and still acts on the female genital system. Final considerations: Is concluded, that melatonina has a fundamental role in the circadian rhythm of the
\end{abstract}

\footnotetext{
${ }^{1}$ Universidade Federal de Pernambuco (UFPE), Recife - PE. *E-mail: diana.babini@gmail.com

2 Universidade Federal da Paraíba (UFPB), João Pessoa - PB.

${ }^{3}$ Faculdade de Comunicação Tecnologia e Turismo de Olinda (FACOTTUR), Olinda - PE.
} 
human as well as in treatment with protective actions in the body, and can be used in research so that there is a greater scientific advance through its applicability in several áreas of health that may be applied in the future in increasingly specific treatment.

Key words: Melatonin, Sleep, Humans, Protection.

\section{RESUMEN}

Objetivo: Describa las principales características de la acción de la melatonina en cuerpo. Revisíon bibliográfica: Actualmente, se han realizado investigaciones para descubrir más y más sobre las acciones de la melatonina (MEL) en humanos. La literatura lo describe como hormona del sueño, fundamental en ritmo circadiano del cuerpo. Varias acciones fisiológicas da MEL, ocurren através de su interacción con receptores de membrana, que se llaman MT1 y MT2. Además, juega un papel importante durante a vida. Alcanzan los valores más altos en niveles séricos en desarrollo infantil y la fase prepuberal. Sufre una disminución progresiva la pubertad, disminuyendo significativamente con envejecimiento. Actualmente, los estudios informan que MEL ha estado mostrando acción antioxidante, antiinflamatoria, antioncostática y también en eliminación de radicales libres. También tiene acción otoprotectora, acción importante sobre la placenta durante el embarazo y aún actúa sobre sistema genital femenino. Consideraciones finales: De esta manera, se concluye que la melatonina tiene un papel fundamental en el ritmo circadiano del cuerpo, así como en tratamiento con acciones protectoras en cuerpo, pudiendo ser utilizada en investigación para que haya un mayor avance científico através de su aplicabilidad. En varias áreas de la salud que pueden aplicarse en futuro en tratamientos más específicos.

Palabras-Ilave: Melatonina, Fotoperiodo, Humanos, Proteccion.

\section{INTRODUÇÃO}

Sousa Neto JA e Castro BF (2008) afirmam que a Melatonina (MEL) é o principal hormônio sintetizado, nos vertebrados, pela pineal, glândula do tamanho de uma ervilha, localizada entre o hipotálamo e a hipófise. Autores como Srinivasan V, et al. (2011), Pinato L, et al. (2017) e Lucheti F, et al. (2010) descrevem que além da glândula pineal, a MEL pode ser sintetizada por outras áreas do corpo, como por exemplo:sistema nervoso, trato gastrointestinal e retina. A MEL, também conhecida como $\mathrm{N}$-acetil-5metoxitriptamina e derivada do aminoácido triptofano, no ano de 1958, foi descoberta por um estudioso chamado Aaron Lerner (LERNER AB, et al., 1958). O pesquisador atribuiu esta nomenclatura a mesma, em decorrência da sua capacidade de contração dos melanóforos de melanócitos de sapos, resultando em um clareamento da pele desses animais (CLAUSTRAT TB, et al., 2005).

Biesalski HK, et al. (1988) descrevem aexistência da síntese deste hormônio no sistema auditivo. Reiter RJ, et al. (2013) afirmam que além de ser sintetizada em diferentes órgãos, uma das explicações para sua ampla distribuição em tecidos, órgãos e fluidos seria sua facilidade em atravessar membranas celulares e barreiras fisiológicas, como a barreira hematoencefálica, apresentando característica anfifílica, ou seja, hidrossolúvel e lipossolúvel.

Maganhin CC, et al. (2008) afirma que a MEL é considerada um composto orgânico, de coloração amarelo-claro, altamente lipossolúvel, além de ser transportada no plasma. A mesma é ligada a proteínas, em especial, à albumina. Sua vida média varia entre 30 e 60 minutos. É derivada da serotonina, a qual, por sua vez, apresenta o aminoácido triptofano como sendo o seu precursor (MAGANHIN CC, et al., 2008).

Sousa Neto JA e Castro BF (2008) afirmam que a MEL se origina do diencéfalo e está localizada entre os dois hemisférios cerebrais (direito e esquerdo) mais especificamente no teto do terceiro ventrículo. Apresenta um peso aproximado de 0,13 gramas e tamanho em torno de 1,2cm de diâmetro.

Como órgãos de metabilização da MEL temos o fígado e o cérebro (MAGANHIN CC, et al., 2008). Sousa Neto JA e Castro BF (2008) relatam que no fígado há depuração de aproximadamente $90 \%$ dos seus níveis 
circulantes. Os autores ainda afirmam que a 6-sulfatoximelatonina, principal metabólito da MEL, é excretada através da urina humana e seus níveis refletem fidedignamente a atividade biossintética da glândula pineal.

Vale ressaltar que a MEL apresenta um papel importante durante o ciclo da vida. Soares Júnior JM, et al. (2008) afirmam que é durante o desenvolvimento da criança e na fase prépubere que os níveis séricos da MEL atingem os maiores valores. Waldhauser $F$, et al. (1991) relatam que durante a puberdade há uma diminuição progressiva apresentando baixos níveis deste hormônio. Messinis IE (2006) informa que, após este período, os níveis da MEL sofrem variações cíclicas na mulher até a perimenopausa, quando ocorre uma pequena elevação. Por fim, existem evidências de que a síntese de MEL e seus níveis séricos decrescem com o envelhecimento do indivíduo.

Normalmente a MEL é sintetizada e secretada à noite, por volta de 02 horas antes do horário habitual do indivíduo ir dormir (LACK LC e WRIGHT HR, 2007), atingindo os níveis plasmáticos máximos por volta de 03:00 a 04:00 horas após o início do sono. Vale ressaltar que isso vai variar de acordo com o cronótipo do indivíduo. Depois a MEL ser secretada, a mesma é distribuida por vários tecidos corporais não sendo estocada (REITER RJ, 1991). Autores como Nosjean O, et al. (2001) ainda afirmam que a síntese e secreção da melatonina em todos os mamíferosé estimulada pelo escuro e inibida pela luz.

Diante do exposto, essa revisão de literatura traz como objetivo descrever as principais características sobre a atuação da melatonina no corpo humano, para que cada vez mais haja informações sobre essa substância tão importante e ao mesmo tempo pouco conhecida para os sistemas do corpo.

\section{REVISÃO BIBLIOGRÁFICA}

\section{Principais características sobre a melatonina, ritmos biológicos e sono}

A melatonina (MEL) ou "hormônio da escuridão" é conhecida, segundo Reiter RJ (1991), por suas interações funcionais com o eixo neuroendócrino e com os ritmos circadianos do corpo humano, ou seja, o ciclo biológico de $24 \mathrm{~h}$ em que há influência da variação de luz, temperatura, marés e ventos entre o dia e a noite. Ele fornece ao organismo a informação de que é noite. Além disso, é um cronobiótico, ou seja, substância que sincroniza os ritmos biológicos intrínsecos. É importante salientar que, quando o hormônio ésecretado em horários diferentes do habitual, ou seja, do fisiológico do indivíduo, normalmente ocorre um aumento da sonolência bem como uma diminuição da temperatura corporal (SOUSA NETO JA, CASTRO $\mathrm{BF}, 2008)$.

Dentre os fatores ambientais, a luz é considerada como sendo o fator mais importante no processo de regulação tanto da síntese de MEL como também responsável pelo ritmo circadiano de sua secreção. Os autores relatam que o núcleo circadiano é suscitado no núcleo supraquiasmático do hipotálamo. Lá, há uma atuação da luz como um oscilador circadiano endógeno, uma vez que estudos demonstraram que, quando isolado de outras estruturas do encéfalo, seus neurônios mantêm o funcionamento do mesmo (ZEE PC, MANTHENA P, 2007).

Conforme Zeitzer JM, et al. (2000) a luz consegue inibir a ação da glândula pineal, realizada pela seguinte via: os neurônios da retina são excitados por impulsos luminosos. Esses neurônios fazem conexão com o núcleo supraquiasmático através do trato retinohipotalâmico, onde suas fibras são classificadas como glutamatérgicas.

Projeções inibitórias partem do núcleo supraquiasmático, que se conectam ao núcleo dorsomedial do hipotálamo e conseguem controlar os ritmos circadianos que apresentam uma relação com o ciclo sonovigília, com atividades locomotoras, com a alimentação e, por fim, com a síntese de corticosteroides (GILBERT SS, et al., 1999). Conforme Sousa Neto JA e Castro BF (2008), esses núcleos se projetam, sejam de forma direta ou indiretamente na região torácica alta da coluna, mais especificamente na medula espinhal, sobre os neurônios pré-ganglionares simpáticos. Estes enviam seus axônios aos gânglios cervicais superiores, os quais pelos ramos carotídeos internos e nervos conários, que secretam noradrenalina e máxima atividade dos receptores alfa e beta adrenérgicos, projetando-se maciçamente sobre a glândula pineal (Figura 1). 
Kleitman N (1963) descreve que durante o dia, ou seja, no período de luz, o núcleo supraquiasmático do ser humano encontra-se ativo. Em decorrência da presença de sua ação inibitória gabaérgica sobre o núcleo paraventricular, a estimulação noradrenérgica da pineal fica inexistente. Já durante a noite, ou seja, na fase escura, o núcleo supraquiasmático está inativo e, portanto, passa a existir uma ativação da glândula pineal.

Figura 1 - Esquema evidenciando as conexões neurais para a glândula pineal.

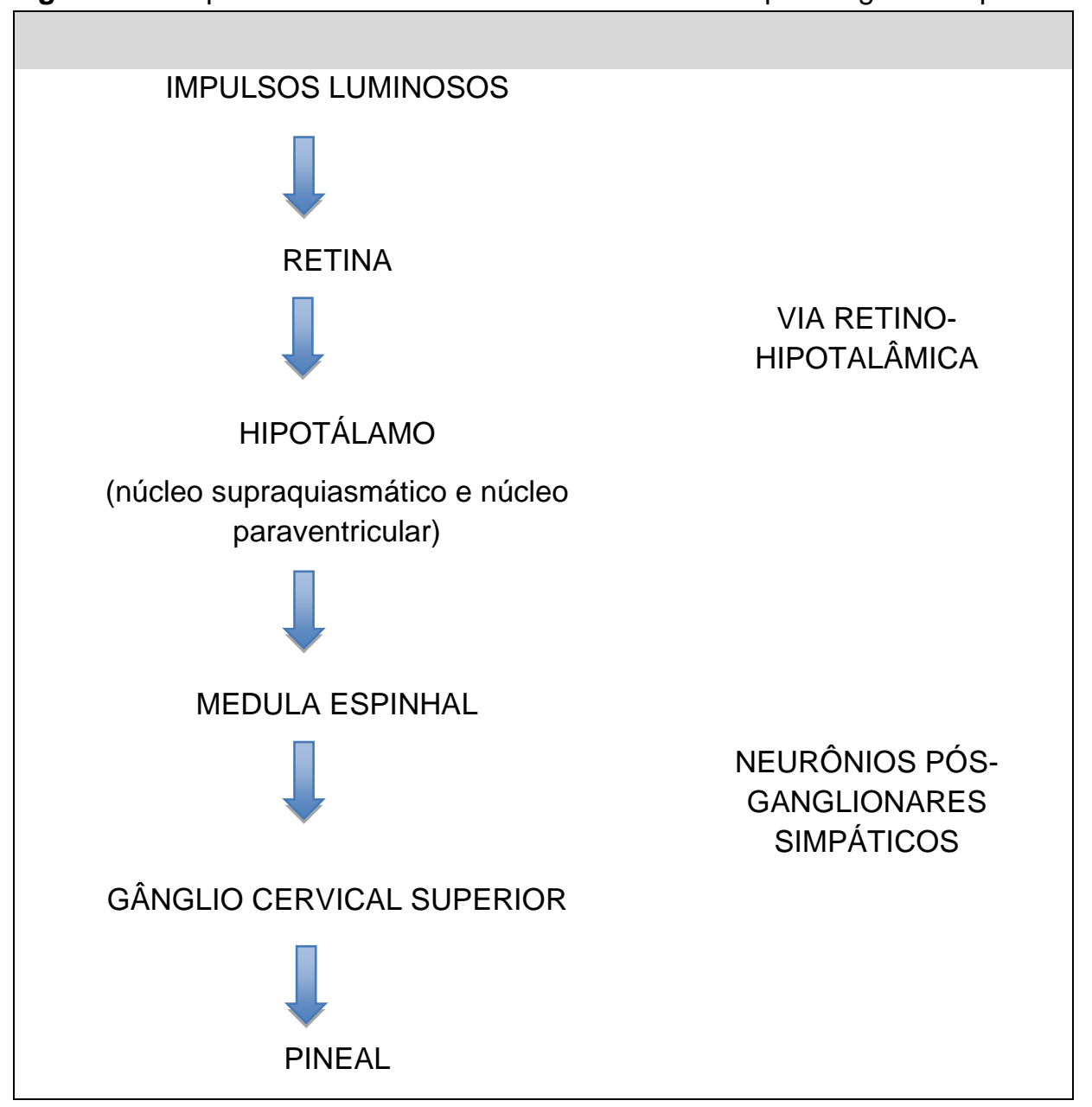

Fonte: Britto DBLA, et al., 2020. Adaptado de Cavallo A, 1993.

Maganhin CC, et al (2008) afirmam que, fisiologicamente, muita das ações da MEL ocorre através da interação com receptores de membrana acoplados a proteína $G$, que são receptores específicos chamados de MT1, MT2 e MT3. No entanto, autores como Nosjean O, et al. (2001) questionam se o receptor Mt3 de fato existe como um receptor ou se ele é uma enzima chamada redutase quinona 2. Os autores descrevem que o MT3 ainda não foi encontrado em seres humanos, porém existem em hamsters. Por fim, Slominski RM, et al. (2012) afirmam que os receptores MT1 e MT2 são encontrados e/ou distribuídos tanto no sistema nervoso central (SNC) como no sistema nervoso periférico (SNP).

O receptor MT1 (Mel1c) são expressos no cérebro, sistema cardiovascular, sistema imunológico, testículos, ovários, pele, fígado, córtex adrenal, placenta, mama, retina, pâncreas e baço. Vale salientes que, no cérebro, o receptor é predominantemente encontrado no hipotálamo, cerebelo, hipocampo, substância negra e área tegmentar ventral (SLOMINSKI RM, et al., 2012; PANDI-PERUMAL SR, et al., 2008). Já o receptor MT2 foi encontrado no sistema imunológico, cérebro, retina, hipófise, vaso sanguíneo, testículos, rim, trato gastrointestinal, glândulas mamárias, tecido adiposo e pele humana (SLOMINSKI RM, et al., 2005a). 
Por fim, Nosjean O, et al. (2001) afirmam que, embora o receptor MT3 não seja encontrado em humanos, ele encontra-se presente em hamster, sendo o mais alto nível deste detectado ao nível do fígado, rins, coração, tecido adiposo e cérebro. Reiter RJ (2013) descrevem que as ações da MEL podem ser mediadas por receptores de membrana, receptores nucleares ou até de ações intracelulares diretas.

Em relação ao sono, sabe-se que ele é descrito como uma necessidade fisiológica primordial. Além disso, o sono oferta uma vida mais saudável, uma melhor qualidade de vida, sendo considerado como o repouso que regenera o ser humano, uma vez que durante o sono, ondas cerebrais se alteram permitindo 0 relaxamento do corpo.Em contrapartida, a ausência do mesmo pode acarretar transtornos de ordem física e mental, comprometendo a qualidade de vida do indivíduo (ROSA RC e BORJA A, 2019).

Rosa RC e Borja A (2019) ainda afirmam que distúrbios do sono podem trazer como consequência ao ser humano, prejuízo no funcionamento normal do corpo, além de poder aumentar as chances de distúrbios no sistema nervoso, alterações psiquiátricas, déficits cognitivos, agravamento de problemas de saúde, riscos de acidentes, dentre outros.Medeiros ALD, et al. (2002) afirmam que além das possíveis alterações descritas acima a diminuição e/ou ausência de sono também pode estar relacionado a doenças como depressão e ansiedade.

Maganhin CC, et al. (2008) descrevem que a MEL influencia diversos processos que se alteram durante à noite. Além do sono que se altera, o processo de digestão se torna mais lento, a temperatura corpórea decresce, tanto o ritmo cardíaco quanto a pressão sanguínea diminuem e o sistema imunológico também é estimulado, sofrendo alteração noturna.

Maganhin CC, et al. (2008) afirmam que a melatonina é considerada uma molécula chave de controle do ritmo circadiano, sendo este controle tanto nos animais como nos seres humanos. Por fim, os autores ainda afirmam que a MEL parece ser capaz de aumentar tanto a mobilidade quanto a atividade das células de defesa, bem como apresenta a capacidade de estimular a produção de anticorpos e facilitar a defesa contra os microrganismos.

Em relação ao sono, sabe-se que a MEL é considerada um regulador natural do mesmo.Costa RM e Martins IS (2016) afirmam, em seu estudo, que existem evidências suficiente para aconselhar a utilização da melatonina no alívio sintomático da Insônia Primária (SOR A) e na melhoria da qualidade de vida (SOR B).

Costa RM e Martins IS (2016) ainda relatam que existem diversos fármacos de diferentes classes com evidência em tratamento da insônia, porém, ao contrário desses medicamentos de uso corrente, a MEL através da libertação prolongada parece apresentar baixo risco de dependência, não apresentando efeitos colaterais após a suspensão do uso no tratamento.

É importante ressaltar ainda que a melatonina é considerada um ressincronizador do sono e o mesmo tem sido referido como uma alternativa terapêutica no tratamento da Insônia Primária individuos com idade a partir dos 55 anos, uma vez que esse hormônio tende a diminuir de produção durante a senilidade do ser humano (HAIMOV I, et al., 1994).

Contudo, são necessários mais estudos, com metodologias rigorosas e seguimento a longo prazo, para obtenção de resultados mais consistentes. Souza Neto JAS e Castro BF (2008) relatam que a MEL também pode melhorar a qualidade sono dos indivíduos, bem como a promoção de uma sonolência que se assemelha ao padrão fisiológico. Além disso, o indivíduo não apresenta a presença de efeitos colaterais, diferentemente de diversas drogas hipnóticas, como os benzodiazepínicos. É por isso que a MEL cada vez mais vem sendo considerada altamente promissora no uso de tratamentos relacionados à distúrbios de insônia.

Rosa RC e Borja A (2019) afirmam que dentre os fármacos utilizados para combater a insônia se encontra a melatonina, um dos medicamentos e/ou suplementos com menor índice de efeitos colaterais. Os autores ainda relatam que além do controle do ciclo do sono, a MEL vem sendo usada para melhorar o sistema imunológico, a redução do envelhecimento das células e a prevenção do cancer. 


\section{Efeito protetor da melatonina no corpo humano}

A melatonina por muito tempo foi conhecida principalmente por seu papel tanto nos ciclos circadianos quanto na regulação do sono. Atualmente a MEL vem sendo descoberta como tendo ação antioxidante, anti-inflamatória, antioncostática e, também, na eliminação de radicais livres (ZHANG HM eZHANG Y, 2014).

Em relação a ação da MEL no sistema auditivo, até hoje poucos são os estudos que exploram e/ou já exploraram a função dela e seus receptores neste sistema do corpo humano. Em 1989, Rivkees SA, et al. Caracterizou em cérebro de aves a presença de receptores da MEL nos núcleos da via auditiva. Um outro estudo em 2015 realizado por Lacoste B, et al. (2015) investigaram a expressão de MT1 e MT2 no cérebro de roedores em idade adulta, onde descreveram a presença do receptor MT2 no colículo inferior.

Além da presença de neurotransmissores no sistema auditivo central (SAC), existe a presença de moléculas circulantes ou mesmo sintetizadas em estruturas da via auditiva. Biesalski HK, et al. (1988) descreveram aexistência da síntese deste hormônio no sistema auditivo, mais especificamente no Órgão de Corti, na membrana basilar, no nervo coclear e, também, no ligamento espiral, porém sua funcionalidade ainda desconhecida. Demir MG, et al. (2015) ainda relatam que a administração por via oral da MEL em indivíduos, pode via a minimizar, no sistema auditivo, sintomas como: zumbido e efeitos da perda auditiva por ototoxicidade.

Santos GLS (2019) descreve que, dentre as possíveis formas de tratamento e/ou prevenção de alterações auditivas na senilidade, está a suplementação com substâncias antioxidantes e/ou neuroprotetoras que possam retardar a perda neuronal e/ou alterações funcionais dos neurônios. Dentre estas, o hormônio melatonina, tem demonstrado importante ação antioxidante e otoprotetora.

Santos GLS (2019), em seu estudo, detectou um aumento da imunorreatividade dos receptors MT1 e MT2, ao longo do SAP e SAC, indicandp assim um efeito compensatório na senilidade, uma vez que durante essa fase da vida do ser humano a síntese da MEL, produzida pela glândula pineal e liberada na corrente sanguínea tende a diminuir. Por fim, a autora também descreve em seu estudo que pode haver um aumento do número de receptores deste hormônio como forma de compensação da queda da MEL na senescência.

Tavanai E e Mohammadkhani G (2017) relatam que a ação oxidante da MEL ocorre através da eliminação de radicais livres, bem como pelo aumento da capacidade de defesa de muitas enzimas com ação antioxidante, como, por exemplo, $p$ superóxido dismutase, a glutationa peroxidase e, o óxido nítrico sintase. E importante salientar que, essas ações acontecem independentemente dos receptors MT1 e MT2. No entanto, Pinato L, et al. (2015) afirmam que locais de ação neuroprotetoras exercida pela MEL em locais do corpo humano, como cerebelo e hipocampo, são sim dependentes dos seus respectivos receptors.

Um outro fator importante em relação a MEL no corpo humano é que durante a gestação, ocorre uma ampla modulação tanto da função do sistema imune inato quanto do sistema humoral (ARAUJO ACC, et al., 2013). A modulação do sistema imune pode ser afetada, por diversos fatores, dentre eles a presença do hormônio MEL.

Este hormônio parece estimular o sistema imunológico aumentando a mobilidade e a atividade das células de defesa do corpo humano. Com isso há uma melhor formação dos anticorpos que trará como consequência o aumento de defesa contra os microrganismos (CLAUSTRATTB, et al., 2005).

Nakamura $Y$, et al (2001), relatam que durante o período gestacional, em seres humanos, a concentração sérica de melatonina mostram mudança gradual e atingem valores elevados no plasma, atingindo valores elevados ao final desse período, sugerindo que esse hormônio desempenhe importante papel na manutenção da gestação. Esse hormônio atravessa a placenta livremente sem sofrer alteração, atingindo a circulação fetal com facilidade e fornecendo, assim, informações para o feto. Assim, a MEL influencia o fotoperíodo pré-natal por meio dos receptores em diversos tecidos, mediando as interações fisiológicas fetais, entre elas as funções imunológicas (GOLDMAN BD, 2003). 
Voiculescu SE, et al. (2014) afirmam que tanto o embrião como o feto, durante a fase gestacional, são dependentes de melatonina materna, que atravessa livremente todas as barreiras fisiológicas sem mudanças, incluindo a placenta. Os autores relatam dizem que durante o período gestacional aumentam as concentrações de melatonina no sangue materno. Além disso, há evidências que existea presença de melatonina no líquido amniótico.

Outra informação relevante descrita por Graham LH, et al. (2004) é que a MEL apresentado um papel fundamental na função reprodutiva tanto em animais sazonais como nos animais não sazonais, caracterizando-se pela regulação na produção de estrógeno e progesterona, inibição da contratilidade uterina, regulação da atividade funcional e crescimento ovarianoe diminuição de gonadotrofinas $(\mathrm{GnRH})$ que regulam a concentração de hormônio folículo-estimulante (FSH) e hormônio luteinizante (LH). Soares Júnior $\mathrm{JM}$, et al. (2008) descrevem que a melatonina também atua na adenohipófise, mais especificamente nas células que produzem a prolactina (PRL). Outra informação relevante trazida pelos autores é que a MEL também tem ação no balanço hidroeletrolítico, pois enquanto o FSH e LH age mem ações biológicas e concentram-se no sistema genital, a PRL age nos processos metabólitos e no balanço hídrico do corpo humano.

Durante o ciclo menstrual, pesquisa indica que os níveis do hormônio MEL flutuam. Ele apresenta-se em níveis mais baixos durante o período ovulatório e eleva-se nos dias, atingindo níveis mais altos durante a menstruação (SOARES JÚNIOR JM, et al., 2008). Ainda em relação a MEL sabe-se que também que ela é uma eliminadora de espécie reativa de oxigênio (ROS) (MOTA LHCM, et al., 2014) e age como um potente antioxidante, evitando o estresse oxidativo em folículos ovarianos durante a maturação oocitária e 0 desenvolvimento embrionário (TSANTARLIOTOU MP, et al., 2007).

Durante o processo de reprodução, a MEL concentra-se em ações diretas nos ovários. È importante ressaltar que, de acordo com Mota LHCM, et al. (2014), este hormônio pode aliviar de forma eficaz o envelhecimento do oócito produzido in vitro, ritardando, desta forma, o início da apoptose e consequentemente evitando a fragmentação cellular. Além disso, a melatonina tem um papel fundamental no processo do metabolismo lipídico, na gestação, durante o parto e na função do corpo lúteo (MOTA LHCM, et al., 2014). Os autores ainda afirmam que no fluido folicular dos seres humanos são encontrados altos níveis de melatonina e estes aumentam de acordo com o crescimento follicular (NAKAMURA Y, et al., 2001). Em concentrações pré-ovulatórias a MEL também é encontrada em concentrações mais elevadas que quando comparadas com os níveis séricos no plasma. Sabe-se ainda que as concentrações de melatonina no fluido folicular aumentam de acordo com o crescimento folicular.

Maganhin CC, et al. (2008) relatam que a MEL também atua em fase crônica de processo inflamatório, pois ela atua como modulador de respostas inflamatórias e imunológicas. Desta forma, o padrão do processo inflamatório normalmente é restaurado após a reposição da melatonina, em doses farmacológicas, adicionada à água, oferecida apenas na fase do escuro. Já nas inflamações pulmonares alérgicas e/ou asma brônquica, a melatonina tem efeito pró-inflamatório.

Del Rio B, et al. (2004) afirmam que a melatonina também possui ação inibidora endógena, especificamente para receptores alfa de estrogênio via calmodulina. Essa ação reduz a influência do estrogênio em desenvolvimentos tumorais, uma vez que a MEL bloqueia a ação da calmodulina, antagonizando, desta forma, a ação do estrogênio em neoplasias.

\section{CONSIDERAÇÕES FINAIS}

Conclui-se, desta forma, que a melatonina apresenta diminuição com o avanço da idade, tem uma atuação importante no ritmo circadiano, ação sobre o ciclo sono-vigília e reprodução do corpo humano. É sensível à luminosidade tem uma elevada produção no início da noite e uma baixa na produção no início da manhã. Apresenta um papel importante no tratamento com ações protetoras no corpo, podendo, ser utilizado em pesquisas para que haja um maior avanço científico através da sua aplicabilidade em diversas áreas da saúde que poderão ser aplicadas futuramente em tratamento cada vez mais específico. 


\section{REFERÊNCIAS}

1. ARAUJO ACC, et al. Ação da melatonina sobre a dinâmica sanguínea de ratas prenhes e sobre a histogênese do baço e do timo da prole. Arq. Bras. Med. Vet. Zootec., 2013; 65(2): 404-414.

2. BIESALSKI HK, et al. Melatonin and other serotonin derivatives in the guinea pig membranous cochlea. Neurosciense Letters., 1988, 91:41 - 46.

3. CAVALLO A. The pineal gland in human beings: relevance to pediatrics. J. Pediatrics. 1993; 123(6): 843851.

4. CLAUSTRAT TB, et al. The basic physiology and pathophysiology of melatonina. Sleep Med Rev. 2005, 9:11-24.

5. COSTA RM, MARTINS IS. Melatonina na insônia primária: Quais as evidências? Rev Bras Med Fam Comunidade. 2016;11(38):1-9.

6. DEL RIO B, et al. Melatonin, an endogenous-specific inhibitor of estrogen receptor alpha via calmodulin. J Biol Chem. 2004;279(37):38294-38302.

7. DEMIR MG, et al. Effect of Transtympanic Injection of Melatonin on Cisplatin-Induced Ototoxicity. $\mathbf{J}$ Int Adv Otol., 2015; 11(3): 202-206.

8. GILBERT SS, et al. Daytime mealtonin and temazepam in young adult humans: equivalent effects on sleep latency and body temperatures. J Physiol. 1999; 514(3): 905-914.

9. GRAHAM LH, et al. Influence of oral melatonin on natural and gonadotrophin- induced ovarian function in the domestic cat. Theriogenology, 2004; 61: 1061-1076.

10. GOLDMAN BD. Pattern of melatonin secretion mediates transfer of photoperiod information from mother to fetus in mammals. Science's STKE., 2003;192: 29-31.

11. HAIMOV I, et al. Sleep disorders and melatonin rhythms in elderly people. BMJ. 1994; 309(6948): 167.

12. KLEITMAN N. Sleep and wakefulness. Chicago: The University of Chicago Press. 1963.

13. LACK LC, WRIGHT HR. Chronobiology of sleep in humans. Cell Mol Life Sci. 2007, 64:1205-1215.

14. LACOSTE B, et al. Anatomical and cellular localization of melatonina MT1 and MT2 receptors in the adult rat brain. J Pineal Res., 2015; 58: 397 - 417.

15. LERNER AB, et al. Isolation of melatonin, a pineal factor that lightens melanocytes. J Am Chem Soc. 1958, 80:2057-2058.

16. LOPEZ-GONZALES MA, et al. Sulpiride and melatonin decrease tinnitus perception modulating the auditolimbic dopaminergic pathway. J Otolaryngol., 2007;36(4): 213-219.

17. LUCHETTI F, et al. Melatonin signaling and cell protection function. The FASEB Journal, 2010, 24(10):36033624.

18. MAGANHIN CC, et al. Efeitos da melatonina no sistema genital feminino: breve revisão. Rev. Assoc. Med. Bras, 2008;54(3).

19. MEDEIROS ALD, et al. Hábitos de sono e desempenho em estudantes de medicina. Revista Saúde - Centro de Ciências da Saúde (UFRN). 2002; 16: 49-54.

20. MESSINIS IE. From menarche to regular menstruation: endocrinological background. Ann N Y Acad Sci. 2006;1092(12):4 9-56.

21. MOTA LHCM, et al. Melatonina e desenvolvimento embrionário. Rev. Bras. Reprod. Anim. 2007; 38(4): 220224.

22. NAKAMURA $Y$, et al. Changes of serum melatonin level and its relationship to feto-placental unit during pregnancy. J. Pineal Res. 2001; 30: 29-33.

23. NOSJEAN O, et al. Comparative pharmacological studies of melatonin receptors: MT1, MT2 and MT3/QR2. Tissue distribution of MT3/QR2. Biochemical Pharmacology. 2001, 61: 1369-1379.

24. PANDI-PERUMAL SR, et al. Physiological effects of melatonin: role of melatonin receptors and signal transduction pathways. Prog. Neurobiol. 2008, 85: 335-353.

25. PINATO L, et al. Day/night expression of $\mathrm{MT}_{1}$ and $\mathrm{MT}_{2}$ receptors in hypothalamic nuclei of the primate Sapujus apella. Journal of Chemical Neuroanatomy. 2017; 81: 10-17.

26. REITER RJ. Pineal melatonin: cell biology of its synthesis and of its physiological interactions. Endocr Rev., 1991,12: 151-180.

27. REITER RJ, et al. Peripheral reproductive organ health and melatonin: ready for prime time. International Journal of Molecular Sciences., 2013;14(4): 7231-7272.

28. RIVKEES SA, et al. Melatonin receptors in chick brain: characterization and localization. Endocrinology., 1989; 125(1): 363-368. 
29. ROSA RC, BORJA A. O uso da melatonin ana insônia. Revista Acadêmica Oswaldo Cruz. 2019; 6(23): 1-11.

30. SANTOS GLS. expressão de proteínas ligantes de cálcio e receptores de melatonina em centros encefálicos da via auditiva no envelhecimento. SP. Dissertação (Mestrado em Fonoaudiologia) - Faculdade de Filosofia e Ciências - UNESP - Campus de Marília, São Paulo, 2019; 67 p.

31. SOARES JÚNIOR JM, et al. Melatonina e puberdade: quais as evidências? Rev Bras Ginecol Obstet. 2008; 30(10):483-5.

32. SOUSA NETO JA, CASTRO BF. Melatonina, ritmos biológicos e sono - uma revisão de literatura. Rev Bras Neurol, 2008; 44 (1): 5-11.

33. SRINIVASAN V, et al. Melatonin in mitochondrial dysfunction and related disorders. International Journal of Alzheimer's Disease., 2011, 2001(326320): 1-16.

34. SLOMINSK RM, et al. Melatonin membrane receptors in peripheral tissues: distribution and functions. Molecular and cellular endocrinology. 2012, 351: 152-166.

35. TAVANAI E, MOHAMMADKHANI G. Role of antioxidants in prevention of age-related hearing loss: a review of literature. Eur Arch Otorhinolaryngol. 2017; 274(4): 1821-1834.

36. TSANTARLIOTOU MP, et al. The effect of melatonin on bovine in vitro embryo development. Ital J Anim Sci, 2007;6: 488-489.

37. ZEE PC, MANTHENA P. The brain's master circadian clock: implications and opportunities for therapy of sleep disorders. Sleep Med Rev. 2007;11: 59-70.

38. ZEITZER JM, et al. Absence of detectable melatonin and perservation of cortisol and thyrotropin rhythms in tetraplegia. J Clin Endocrinol Metab. 2000; 85:2189-2196.

39. ZHANG HM, ZHANG Y. Melatonin: a well-documented antioxidant with conditional pro-oxidant actions. Journal of Pineal Research, 2014; 57(2): 131-146.

40. WALDHAUSER F, et al. Serum Melatonin in Central Precocious Puberty Is Lower than in Age-Matched Prepubertal Children. Journal of Clinical Endocrinology and Metabolism. 1991; 73(4): 793-796. 